Case Report

\title{
An Unusual Association: Arnold Chiari Deformity and Meniere's Disease
}

\author{
do Santos Zounon Alexis ${ }^{1,2, ~}{ }^{\text {, }}$ Molher Joffrey ${ }^{2}$, Bonnard Damien ${ }^{2}$, Darrouzet Vincent ${ }^{2}$ \\ ${ }^{1}$ Department of Otolaryngology Head and Neck Surgery, Military Teaching Hospital, Cotonou, Benin \\ ${ }^{2}$ Department of Otolaryngology Head and Neck Surgery, CHU Bordeaux, University of Bordeaux, Bordeaux, France
}

\author{
Email address: \\ azdosantos@yahoo.fr (do Santos Z. Alexis) \\ ${ }^{*}$ Corresponding author
}

\section{To cite this article:}

do Santos Zounon Alexis, Molher Joffrey, Bonnard Damien, Darrouzet Vincent. An Unusual Association: Arnold Chiari Deformity and Meniere's Disease. International Journal of Otorhinolaryngology. Vol. 4, No. 1, 2018, pp. 21-26. doi: 10.11648/j.ijo.20180401.16

Received: May 23, 2018; Accepted: June 8, 2018; Published: July 12, 2018

\begin{abstract}
Rare and fairly unknown, Arnold Chiari deformity is defined by the abnormally low position of the cerebellar tonsils that engage through the foramen magnum. Its association with the triad of tinnitus-hypoacousia-vertigo causes an authentic Meniere's disease worth discussing. We report an unusual association of Arnold Chiari deformity with Meniere's disease. A 46-years-old patient was diagnosed with left Meniere's disease in 1994 on the classical diagnostic triad and the mode of progression: rotatory vertigo evolving by iterative crises; Intermittent buzzing tinnitus; left perception deafness with notion of wadded left ear. For a decade (1994 to 2015), he has been put under hygieno-dietary measures, vestibular re-education and medical treatment. The evolution was marked by the worsening of vertigo becoming progressively incapacitating, as well as an aggravation of the left deafness and persistence of tinnitus. Audiometry highlighted a severe endocochlear left perception deafness. The videonystagmography revealed a well-compensated left vestibular deficit. Cerebral magnetic resonance imaging (MRI) revealed a cerebellar tonsils' ptosis through the foramen magnum. The diagnosis of Arnold-Chiari deformity associated with Meniere's disease was then retained. The patient received a surgical left labyrinthectomy in 2015 . The clinical course was uneventful, marked by the disappearance of vertigo twenty four months later. Association of Meniere's disease and Arnold Chiari deformity is rare and must be diagnosed. These two pathologies being manifested by peripheral vertigo, a meticulous clinical and Para clinical examination is necessary to guide the diagnosis. Cerebrospinal fluid flow and pressure anomaly due to Arnold Chiari malformation can truly impact labyrinthine physiology, which explains the correlation between these two entities.
\end{abstract}

Keywords: Vertigo, Meniere's Disease, Arnold Chiari

\section{Introduction}

Arnold Chiari disease is due to a mismatch between the size of the skull and that of the brain leading to a malposition of the cerebellum. Rare and fairly unknown, it is defined by the abnormally low position of the cerebellar tonsils that engage for more than $5 \mathrm{~mm}$ [1] through the foramen magnum itself malformed. It can go undetected throughout life or be revealed by very different symptoms $[2,3]$ the most frequent being: posterior headaches, the rmoalgesic and tactile sensitivity disorders and audio-vestibular disorders.

In the other hand Meniere's disease is a chronic affection of internal ear whose reported prevalence rates have varied widely from $3,5 / 100 \quad 000$ to $513 / 100 \quad 000$ according to different authors [4]. Its etiology is uncertain. It has an unpredictable evolution, marked by recurences of episodes of triad tinnitus-hypoacousia-vertigo known in authentic Meniere's disease. It is a potentially an incapacitating afflication due to impact of vertigos on patient's personal, social and professional life. Frequency and evolution of vertigo crisis are randomly: 6 to 11 crisis per year [5]. The diagnosis is primarily based on the clinical history. Clinicians also utilize various tests to confirm the diagnosis based on a consensual guidelines. [6-8]. Peripheral vertigo is common to Chiari deformity and Meniere's disease, their semiological analysis is fundamental to the treatment. We report the case 
of a patient whose main symptom is vertigo and who presents the diagnostic criteria of both pathologies (Arnold-Chiari and
Meniere). Our goal was to report the unusual association of these two pathologies and to expose the therapeutic conduct.

\section{Case Report}
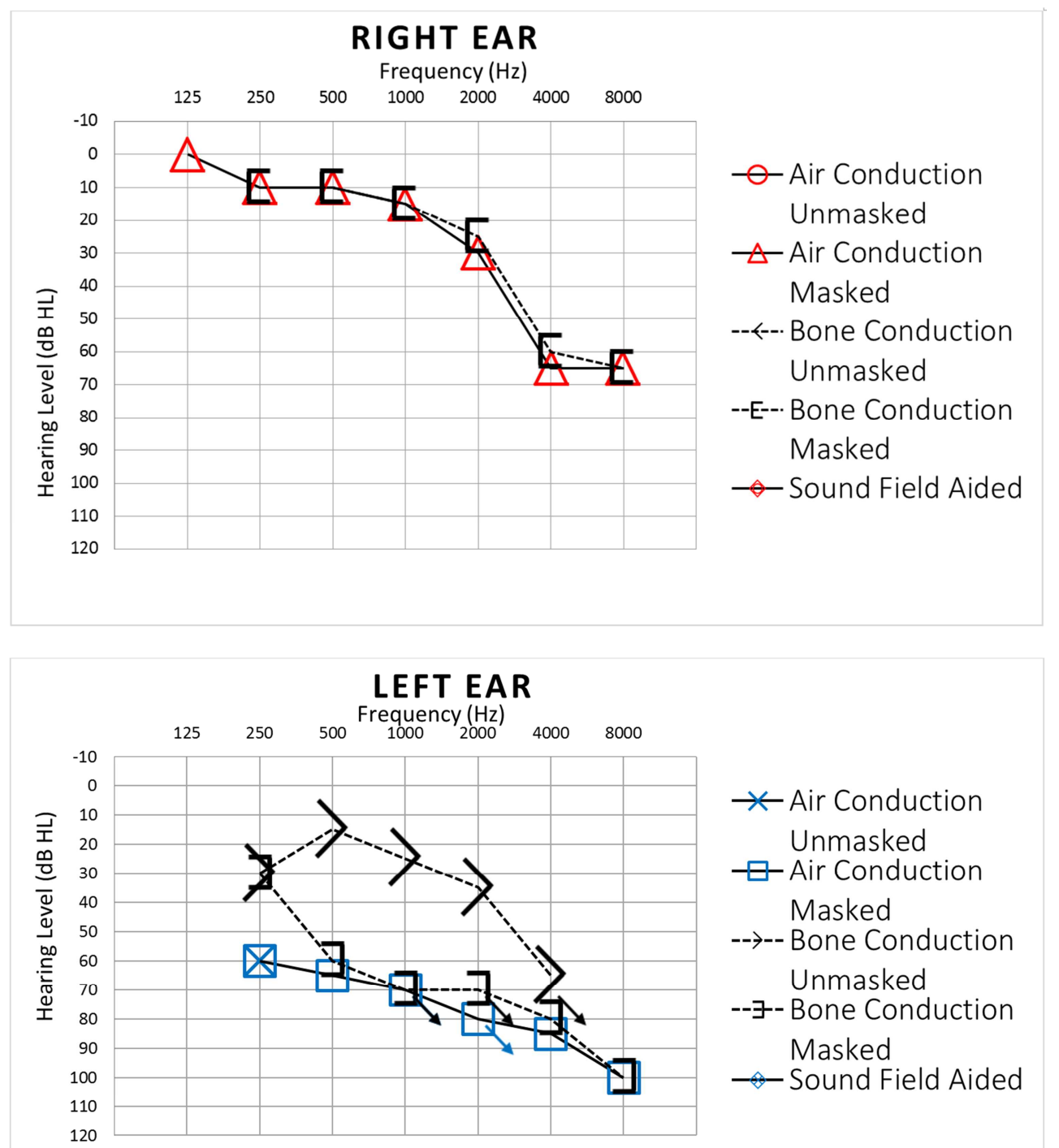

$\rightarrow$ Air Conduction Unmasked 曰-Air Conduction Masked $\rightarrow-\rightarrow-$ Bone Conduction Unmasked ----Bone Conduction Masked $\multimap-$ Sound Field Aided
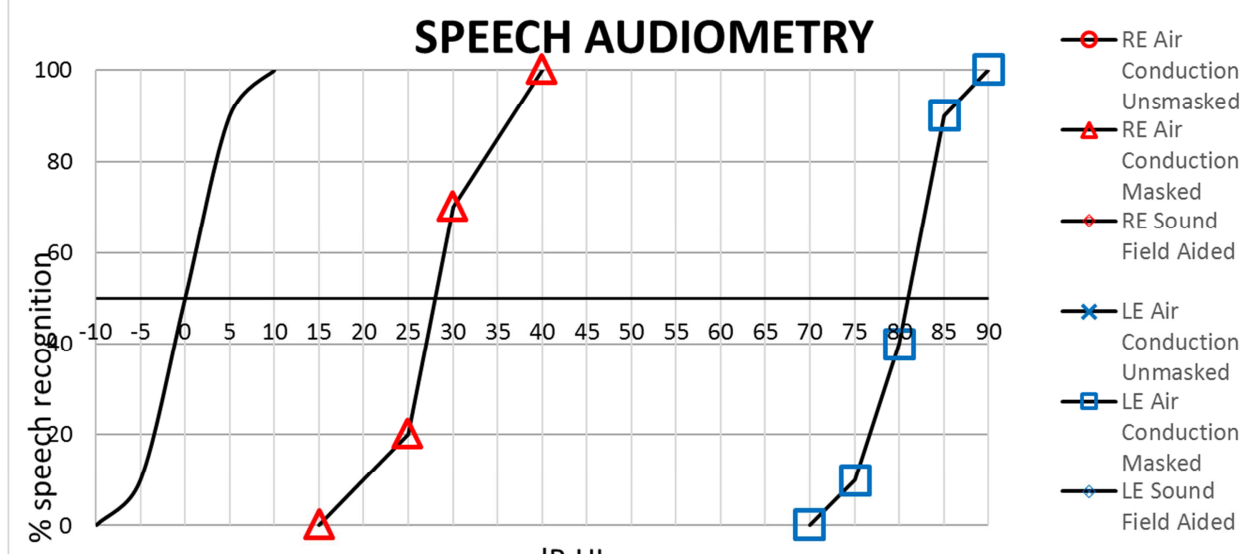

dB HL

Figure 1. Audiometric exploration of the patient. 
A 46-years-old man, married with two children, was referred in 2015 to our university hospital center for incapacitating vertigo evolving for more than ten years. He has a history of smoking (20 Packs-year), dorsal scoliosis, a syringomyelia surgery and an appendectomy. The diagnosis left Meniere's disease was made in 1994 based on the classic diagnostic triad and the mode of progression: rotatory vertigo evolving by iterative crises of more than 20 minutes $(20$ minutes to 6 hours) being repeated 2 to 3 times per week; Intermittent buzzing tinnitus; left Sensorineural hearing loss (SNHL) with notion of wadded left ear. For ten years (1994 2015), he was treated by hygienic and dietary measures (low sodium diet, alcohol, tobacco, and nicotine restriction; and adequate sleep); vestibular re-education and medical treatment (Acetyl-Leucine central anti-vertigo; Acetazolamide osmotic diuretic; Anxiolytics; Betahistine vasodilators). Evolution under this treatment was marked by the aggravation of vertigo becoming progressively incapacitating, as well as a worsening of the left deafness and persistence of tinnitus. An audio-vestibular check-up was done again as soon as he was admitted in August 2015. Audiometry were concordant and showed a severe endocochlear left perception deafness (average hearing loss of $70 \mathrm{~dB}$ predominant for high frequencies, and recruitment) [Figure 1].

Ipsilateral auditory evoked potentials were altered [Figure 2].

Parametres : 2000 acquisitions. Stimulation : clics, avec assourdissement à -20dBs. Casque

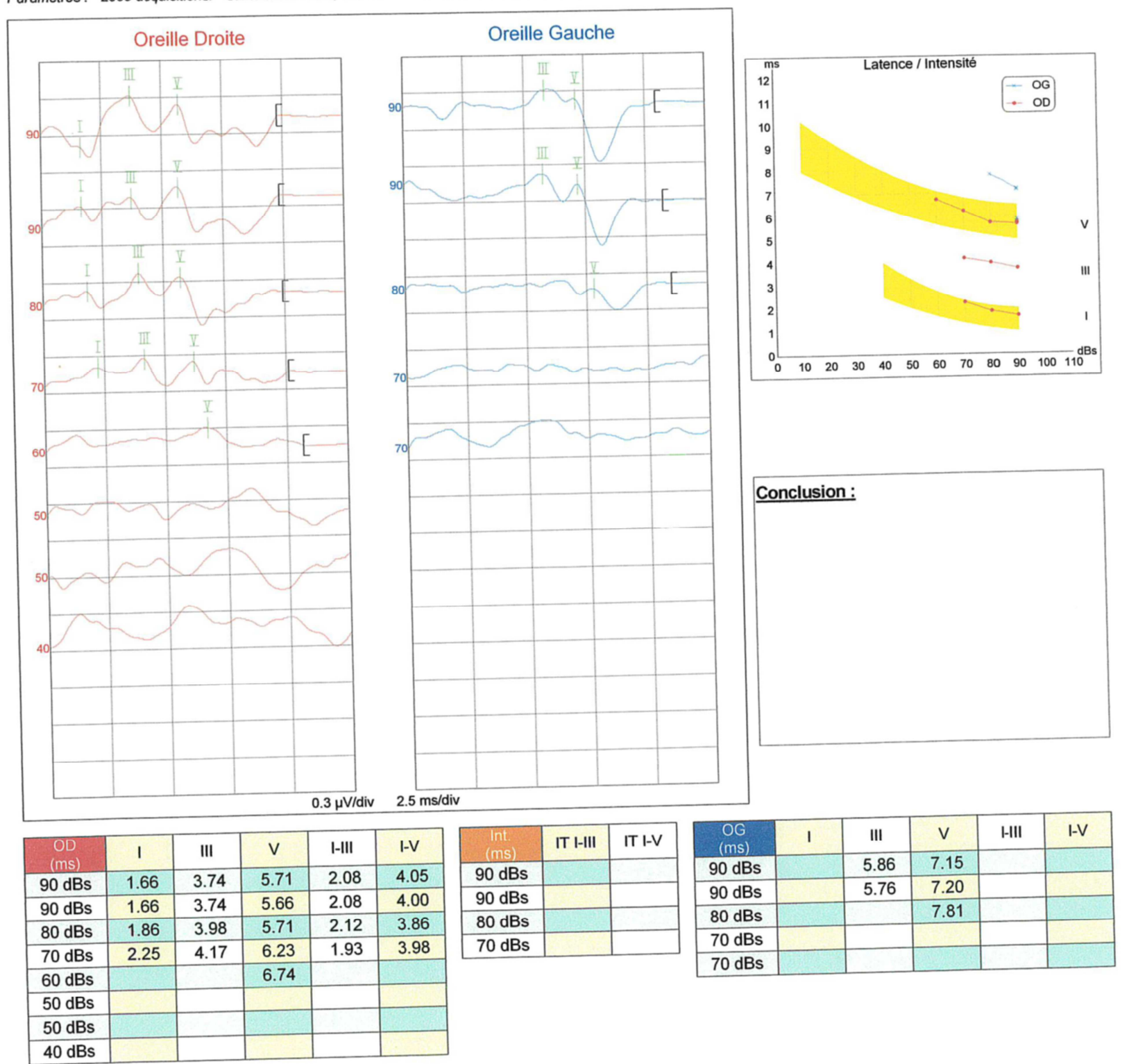

Note: Parameters: 2000 acquisitions Simulation: clicks, with muffling in -20dB; Helmet. Right Ear (red); Left Ear (blue)

Figure 2. Altered auditory evoked potential.

Evoked otolithic potentials confirmed the deficit on the left [Figure 3]. 


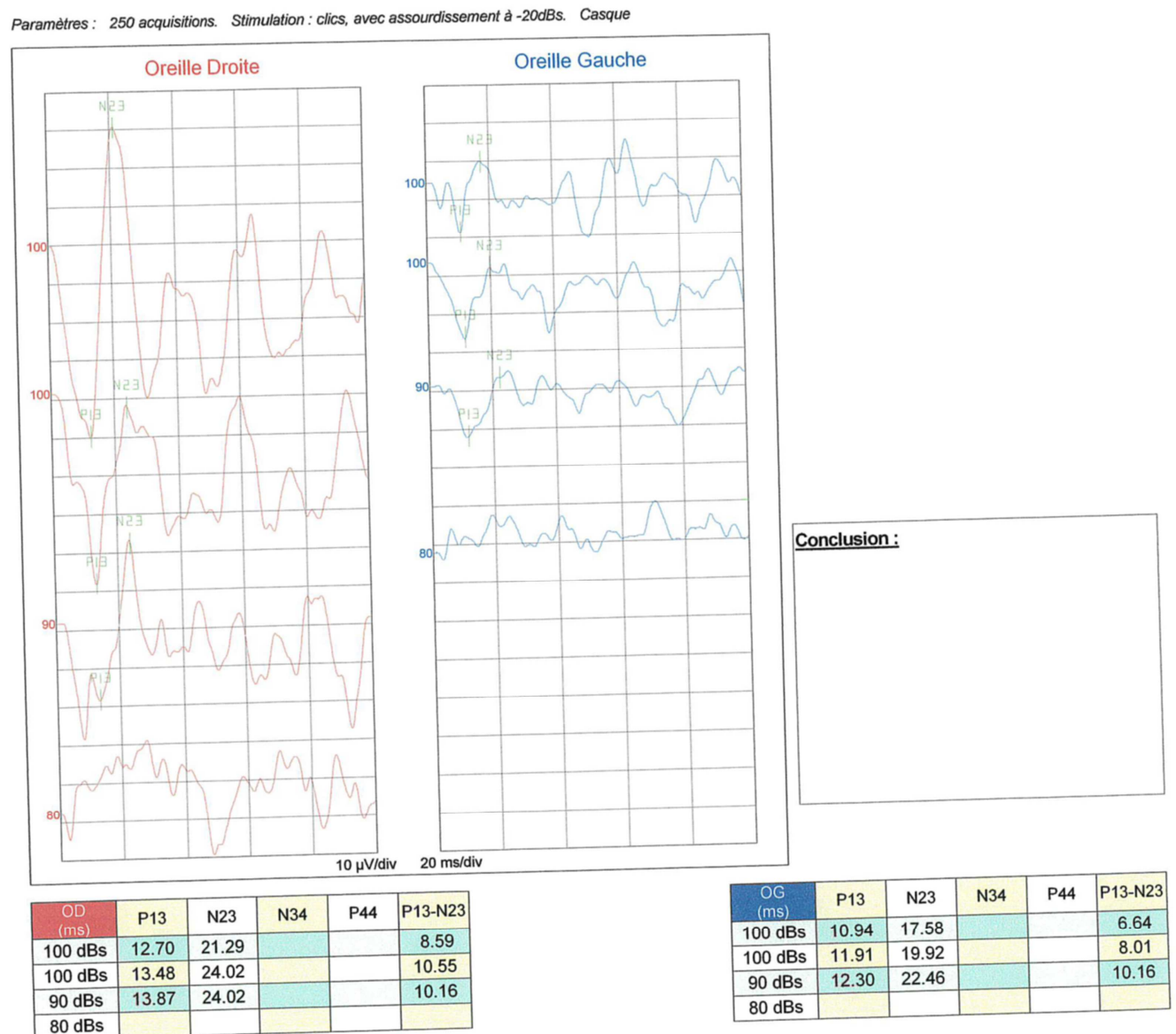

Note: Parameters: 250 acquisitions Simulation: clicks, with muffling in -20dB; Helmet. Right Ear (red); Left Ear (blue)

Figure 3. Altered Otolithic evoked potentials.

Videonystagmography showed well-compensated left vestibular areflexia [Figure 4].

\begin{tabular}{|c|c|c|}
\hline \multicolumn{2}{|c|}{ Resultats } & $\because \mathrm{A}$ \\
\hline \multicolumn{2}{|c|}{$\begin{array}{l}\text { Mode d'affichage } \\
\text { - Horizontal } \\
\text { r Vertical }\end{array}$} & $\begin{array}{c}\text { Tours ficitif } \\
\text { Total } 00 \\
-1.8 \\
\text { Totel }\end{array}$ \\
\hline & $30.0 \% 44.0^{\circ}$ & 0.5 \\
\hline $\begin{array}{l}\text { Débur } \\
\text { Duré }\end{array}$ & $\begin{array}{l}E \text { Eu } \\
10 \mathrm{~s} \\
40 \mathrm{~s}\end{array}$ & (ㄱ) () (9) \\
\hline
\end{tabular}

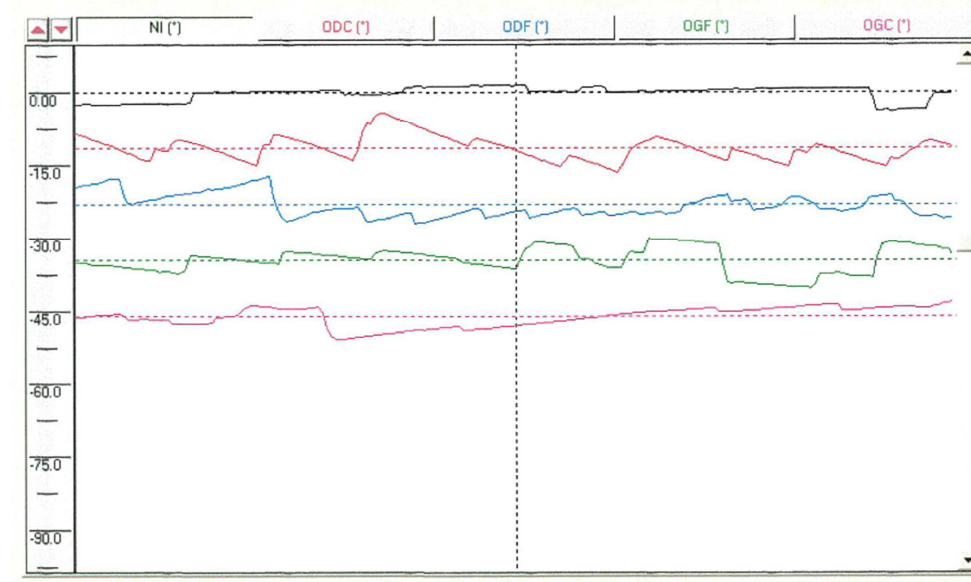

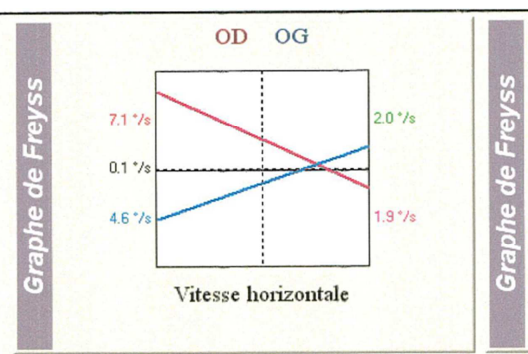

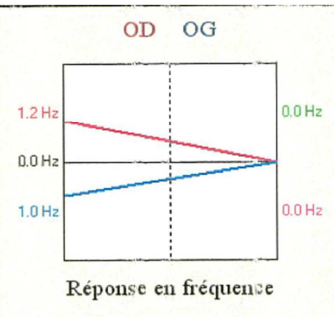

Réflectivité: $11.7 \%$ s (à droite)

Prép. absolue: $0.4 \%$ s (droite)

Prép. relative: $16 \%$ (droite)

Déficit: $50 \%$ (gauche)

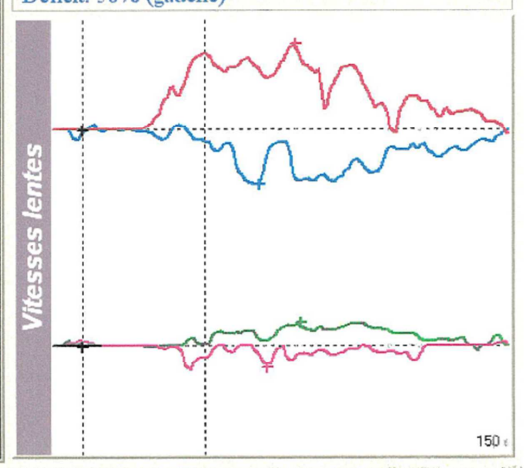

150 :

Figure 4. Videonystagmograph (VNG) of the patient. 
Cerebral magnetic resonance imaging (MRI) revealed a $9,2 \mathrm{~mm}$ cerebellar tonsils' ptosis through the foramen magnum [Figure 5].

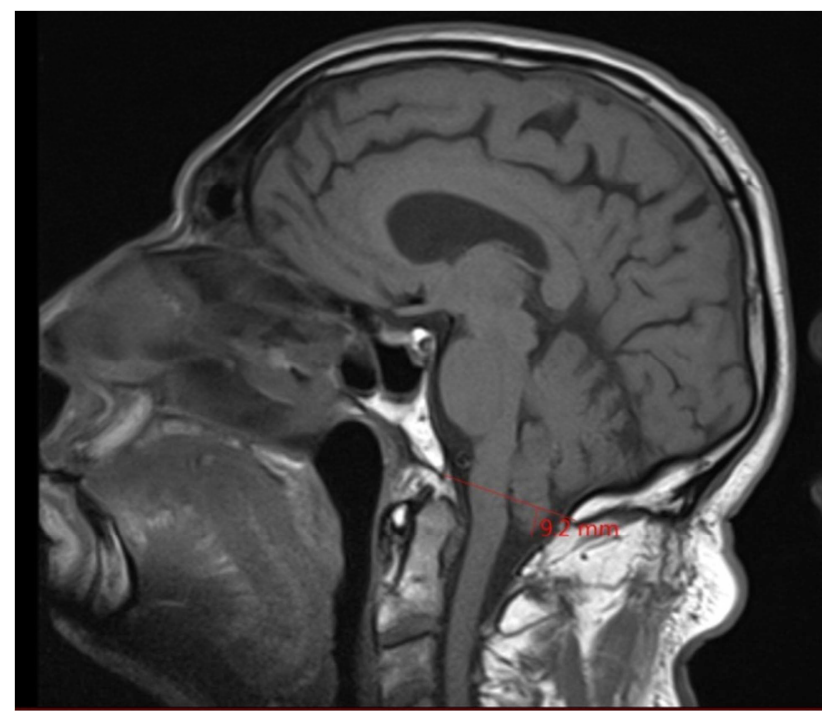

Figure 5. Cerebral magnetic resonance imaging of the patient.

The diagnosis of Arnold-Chiari deformity associated with Meniere's disease was retained. Due to the severity of left hypoacousia and incapacitating vertigo, the patient received a left surgical labyrinthectomy in 2015. The evolution was favorable, marked by disappearance of vertigo and an expected left iatrogenic cophosis. Post-operative follow-up was of twenty four months.

\section{Discussion}

Type 1 Arnold Chiari deformity is defined as a cerebellar tonsils hernia through the foramen magnum of more than 5 millimeters. It is characterized by a malposition of the cerebellum that ends up into the spinal canal often associated with syringomyelia in $40 \%$ to $80 \%$ of cases [9, 10]. Its diagnosis is confirmed by magnetic resonance imaging especially on sagittal sections. When it becomes symptomatic, it is often revealed by a non-specific neurological syndrome including occipital headaches $[11,12]$ and sensory thermo-algesic disorders, balance disorders [13], and more rarely sleep disorders [14]. Its standard treatment is neurosurgical, based on the posterior pit decompression. This surgery is not without risk. [15].

The association with audio-vestibular disorders is not uncommon [16]. And the symptomatology can be menieriform [16]. In our clinical case the intensity of vertigo and the absence of other neurological disorders are not attributable to Arnold Chiari deformity.

The challenge for clinical medicine at this stage is not to ignore an associated Meniere's disease that would require a specific treatment. Careful clinical and Para clinical analysis is essential for diagnosis [17]. Recruitment on audiometry reinforces this diagnosis. It advocates for treatment of
Meniere's disease. The evolution was spread over more than a decade in two successive stages: iterative vertigo at the beginning then chronic and incapacitating vertigo. Labyrinthectomy and vestibular neurotomy are the most effective surgical procedures in case of incapacitating vertigo when it comes to Meniere's disease. Trans-mastoid surgical labyrinthectomy presents less risk of complication than vestibular neurotomy [18]. We chose it because of the incapacitating vertigo and lack of effective hearing. In case audition needs to be preserved, the risk of iatrogenic cophosis due to labyrinthectomy makes endolymphatic sac decompression surgery a preferable option [19] or corticosteroids intratympanic injection [20]. in any diagnosed case of Meniere's disease, it's highly recommended to perform an MRI of the posterior pit and of the cervico-occipital hinge in both axial and sagittal planes in order to exclude other secondary causes of Chiari's deformity [21].

Strengths and Weaknesses

Major strength of our case is the rare association between these two pathologies: Chiari's deformity and Menire's disease. The article emphasizes the diagnostic process based on interrogatory, clinical examination then paraclinic tests. Indeed, taking care of vertigo crisis is sometimes tough, due to symptoms' complexity and various etiologies. The main weakness of any case report remains its isolation, and we can't jump to scientific conclusions. But this case stresses the importance of this possible association and arouses lector's conscience on a meticulous diagnosis process.

\section{Conclusion}

Chiari deformity remains asymptomatic for a long time and discovery is often random. No sign is specific but the posterior cervicalgia, headache and balance disorders are very evocative. This clinical case draws attention to the vertiginous syndrome that can simulate a revelation mode. Clinical and Para clinical analysis led to the conclusion of an associated Meniere's disease and adequate care could be provided. This clinical case draws our attention to the very wide field of etiologies for vertigo. Every clinician should remain critical when encountering vertiginous patients.

\section{References}

[1] Merrow A. M, L'Hariharan S. Imaging in Pediatrics ISBN-13: 978-0323477789. Ebook 424p. Elsevier Canada; 2018: 300-1.

[2] Masson C, Colombani J-M. La malformation de Chiari de type 1 à l'ère de l'imagerie par résonnance magnétique. 2005; 34 (21): 1662-7.

[3] Elster AD, Chen MY. Chiari 1 malformations: clinical and radiologic reappraisal. Radiology 1992; 183: 347-53.

[4] Alexander T. H, Harris J. P. Current epidemiology of Meniere's syndrome. Otolaryngol Clin North Am. 2010; 43: 965-970. 
[5] Weckel A, Marx M, Esteve-Fraysse M. J. Control of vertigo in Meniere's disease by intratympanic dexamethasone. European Annals of Otorhinolaryngology, Head and Neck Diseases. 2018; Volume 135: 7-10.

[6] Nevoux J, Barbara M, Dornhoffer J, Gibson W, Kitahara T, Darrouzet V. International consensus (ICON) on treatment of Ménière's disease. European Annals of Otorhinolaryngology, Head and Neck diseases. 2018; 135: S29-S32.

[7] Committee on hearing equilibrium guidelines for the diagnosis evaluation on therapy in Ménière's disease. Otolaryngol Head Neck Surg. 1995; 113: 181-5.

[8] Lopez-Escamez JA, Carey J, Chung WH, Goebel JA, et al. Diagnostic criteria for Ménière's disease. J vest Res. 2015; 25:1-7.

[9] Noël S, Delavallée M, Scory P, et al. La fatigue comme unique symptôme de la malformation d'Arnold-Chiari. Med Som. 2009; 6: 109-12.

[10] Benjamin M. D, Santiago J, Hebert J. C, Thirion S, Ranaivojaona S, Alvarez C, Atallah A, Sibille G, Bataille H, Porlys M, Ebrad P. Hémi-hypertrophie et scoliose révélatrices d'une malformation de Chiari de type 1 avec syringomyélie. Archives de Pédiatrie. 2011; 18: 1210-5.

[11] Sgouros S, Kountouri M, Natarajan K. Posterior fossa volume in children with Chiari malformation type I. J Neurosurg 2006; 105: 101-6.

[12] Arnett BC. Tonsillar ectopia and headaches. Neurol Clin 2004; 22: 229-36.

[13] Carre G, Mallaret M, Lagha-Boukbiza O, Dietemann JL, Namer I, Anheim M, et al. Malformation d'Arnold-Chiari secondaire à une hyperostose de la voûte crânienne révélée par une ataxie cérébelleuse. Revue Neurologique 2015; 171S: A111-5.
[14] Ferre Maso A, Poca MA, De La Calzada MD, Solana E, Romero Tomas O, Sahuquillo J. Sleep disturbance: a forgotten syndrom in patients with Chiari I malformation. Neurologia 2014; 29 (5): 294-304.

[15] Xiaofeng D, Chenlong Y, Jiahe G, Liang W, Tao Y, Jun Y, et al Long term outcomes after small-bone-window posterior fossa decompression and duraplasty in adults with Chiari malformation type I. World Neurosurg 2015; 84 (4): 998-1004.

[16] Guerra Jimenez G, Mazon Gutierrez A, Marco De Lucas E, et al. Audio-vestibular signs and symptoms in Chiari Malformation type 1. Case series and literature review. Act Otorrinolaringol. Esp. 2015; 66 (1): 28-35.

[17] Muncie HL, Sirmans SM, James E. Dizziness: Approach to evaluation and management. Am Fam Physician 2017. 95 (3): 154-62.

[18] Alarcon AV, Hidalgo LO, Arevalo RJ. Labyrinthectomy and vestibular neurectomy for intractable vertiginous symptoms. Int Arch Otorhinolaryngol 2017; 21 (2): 184-90.

[19] Flores Garcia ML, Llata Segura C, Cisneros Lesser JC, Pane Pianese C. Endolymphatic sac surgery for Meniere's disease. Current opinion and literature review. Int Arch Otorhinolaryngol 2017; 21 (2): 179-83.

[20] Jumaily M, Faraji F, Mikulec AA Intratympanic triamcinolone and dexamethasone in the treatment of Meniere's syndrome. Otol Neurotol 2017; 38 (3): 386-91.

[21] Société Française d'Oto-Rhino-Laryngologie et de Chirurgie de la Face et du Cou. Recommandation pour la pratique clinique. RCP Stratégie diagnostique et thérapeutique dans la maladie de Menière. [Available from: https://www.orlfrance.org/wp-content/uploads/2017/06/Maladi e-de-Meniere-stategie-diagnostique-et-therapeutique.pdf]. 